\title{
Actualización:
}

\section{Parálisis facial idiopática o parálisis de Bell}

\begin{abstract}
Resumen
Causada muy probablemente por el virus del herpes simple tipo I y en algunos casos por el zoster, la parálisis facial periférica mejora luego del tratamiento oral combinado con prednisona y aciclovir (preferentemente en las primeras 72 horas) siendo controvertida su indicación ya que la tasa de recuperación espontánea es alta y sólo unos pocos pacientes no se recuperan si no son tratados. Un $20 \%$ de los casos de parálisis facial aguda tienen una causa diferente a la "idiopática", lo que debe llevar a una cuidadosa evaluación del paciente.

El autor también describe las principales características clínicas y epidemiológicas de la parálisis facial idiopática, así como sus principales diagnósticos diferenciales, otras probables etiologías y los factores pronósticos. Respecto de los tratamiento, hace hincapié en los sustentados por evidencia bibliográfica, mencionando también algunas terapias emergentes.
\end{abstract}

Bauso D. Parálisis facial idiopática o parálisis de Bell. Evid. act. pract. ambul. 9(1): 22-25. En-Febr.2006.

\section{Introducción}

La parálisis facial idiopática o parálisis de Bell, es una parálisis facial aguda, de causa aun incierta, aunque las evidencias actuales más firmes apuntan a una etiología viral. Usualmente el diagnóstico se establece sin dificultad en pacientes que se presentan con una debilidad facial aislada, con semiología periférica, unilateral, e inexplicada.

Existe cada vez mayor certeza de la significativa influencia del tratamiento, en particular en las primeras horas de iniciado el cuadro, sobre las consecuencias finales de la parálisis. Algunos pacientes que no llegan a recibir tratamiento pueden quedar con una disfunción facial mayor y una disminución en su calidad de vida. Una revisión reciente hecha en el Reino Unido afirma que en ese país, de todos los pacientes atendidos con parálisis de Bell por los médicos de atención primaria, solo un quinto fue derivado a un especialista, un poco más de un tercio recibió tratamiento con esteroides por vía oral, y sólo $0,6 \%$ recibieron aciclovir¹).

A fin de mejorar el pronóstico final de los pacientes que sufren una parálisis facial idiopática se requiere de un apropiado reconocimiento de la patología en sus estadíos tempranos y de una adecuada coordinación en la acción entre los especialistas y los médicos generalistas, para que los pacientes puedan ser tratados dentro de las críticas primeras 72 horas de iniciado el cuadro.

\section{Incidencia}

Se considera a la parálisis de Bell como la causante del $75 \%$ de todas las parálisis faciales agudas. La incidencia anual es aproximadamente 20 a 30 por cada 100.000 personas. Tiene un pico de incidencia entre los 15 y 45 años. Los hombres y las mujeres son afectados por igual, aunque la incidencia es mayor en las mujeres embarazadas (45 cada 100.000). El lado izquierdo y derecho se han visto comprometidos en igual proporción.

Tradicionalmente se ha sostenido la existencia de casos estacionales -en particular durante el invierno y por exposición al frío-, sin embargo en estudios epidemiológicos recientes no se encontraron variaciones de este tipo.

En las personas diabéticas existe un exceso de casos de acuerdo a lo esperable. La hipertensión arterial no aparece como un factor predisponente aunque sí parece ser un factor agravante ${ }^{2}$.

\section{Etiología y Fisiopatología}

Existe evidencia creciente que la principal causa de la parálisis de Bell es la reactivación de un virus, herpes, simple tipo I o herpes zoster, que se encontraría latente en los ganglios de los nervios craneales. El ADN del virus herpes, ha sido aislado del nervio facial durante la fase aguda de la parálisis a través de técnicas de PCR (Polymerase Chain Reaction). El herpes zoster tiene un comportamiento biológico más agresivo que el del herpes simple tipo $\mathrm{I}$. La explicación fisiopatológica más aceptada sostiene que el virus herpes inicia un ciclo vicioso de edema, inflamación e isquemia compresiva que involucra al VII nervio dentro de su canal óseo. Se produciría primero una neuropraxia reversible, seguida de una degeneración Walleriana. El canal del facial es comparable a la bóveda craneana, por lo que para mantener el equilibrio en su inte- rior, el aumento de volumen de uno de sus compartimentos debe estar balanceado con una menor proporción en el volumen de otro, y esto no sucede durante la etapa aguda de la infección. Existen otras hipótesis etiológicas menos probables como la vascular, en esta se propone como causa una isquemia secundaria a oclusión arterial. En algunos casos, como en el de los pacientes diabéticos, quizás esta hipótesis pueda tener mayor relevancia.

\section{Clínica}

\section{Síntomas}

El síntoma más prominente es la paresia. Esta debilidad es con frecuencia de inicio súbito y rápida progresión, alcanzándose el máximo de la debilidad dentro de las 48 hs. de iniciado el cuadro. Existen síntomas asociados como alteración en la producción lagrimal y alteración del gusto. Algunos pacientes -entre el 6 y el 29\%sufren de hiperacusia y no pocos de parestesias en el mismo lado de la cara. Hasta la mitad de los pacientes refieren otalgia, sensación de oído tapado, o dolor retroauricular, el cual suele ser leve y puede preceder al inicio de la parálisis.

El dolor intenso sugiere virus de herpes zoster y puede presentar vesículas periauriculares y progresión al síndrome de Ramsay Hunt (ver posteriormente).

Muchos de estos pacientes creen que están sufriendo un accidente cerebro vascular o un tumor intracraneal.

$\mathrm{Si}$ el inicio es lento y se asocia a déficit de otros pares craneales, o si existe cefalea, se deben sospechar otras causas como la presencia de un tumor

\section{Signos}

La parálisis de Bell causa manifestaciones de motoneurona inferior por lesión periférica en el territorio del nervio facial afectado. Clínicamente se manifiesta como una imposibilidad para el movimiento de los músculos faciales y del platisma unilaterales, con desviación de la comisura labial e imposibilidad para ocluir firmemente -a veces aun mínimamente- el ojo y la boca. El fenómeno de Bell -la desviación del ojo hacia arriba cuando se intenta cerrar el párpado- puede verse cuando la oclusión palpebral es incompleta. Una debilidad de origen central causa paresia únicamente de los músculos de la parte inferior de la cara.

Los pacientes con parálisis de Bell requieren un cuidadoso examen neurológico, incluyendo el estado de los otros nervios craneales y la función del tronco cerebral y del cerebelo dado que algunas lesiones centrales, como las de la protuberancia anular ipsilateral, pueden simular un patrón "periférico", en estos casos existen signos y síntomas neurológicos adicionales (Ej. parálisis de VI par). Asimismo debe examinarse la función del oído y buscar la presencia de vesículas. Se recomienda a su vez descartar la existencia de masas faciales o cervicales (Ej: tumor de parótida).

\section{Diagnóstico}

Se han propuesto los siguientes criterios para el diagnóstico de Parálisis de Bell:

1. Inicio súbito de parálisis unilateral completa o parcial de los 
músculos faciales.

2. Ausencia de síntomas o signos de afectación del Sistema Nervioso Central (SNC).

3. Ausencia de síntomas o signos de enfermedad del oído o la fosa posterior.

El diagnóstico es clínico. El primer paso es determinar si la debilidad facial es debida a un problema en el sistema nervioso central o periférico. Esto se hace rápidamente mediante la observación. En los casos de parálisis facial de origen central, la debilidad afecta únicamente la mitad inferior de la cara. Para el diagnóstico de parálisis de Bell se requiere la afectación también de los músculos de la mitad superior de la cara, con limitación de la oclusión ocular y de la actividad de los músculos de la frente.

Los análisis séricos buscando la elevación de los títulos del virus de herpes no son una herramienta diagnóstica confiable para el diagnóstico de la parálisis de Bell.

Los análisis de laboratorio no son esenciales, y en general son normales, por lo que habitualmente no se los solicita. No hay evidencia de que deba estudiarse rutinariamente la presencia de diabetes o de sífilis. En algunos casos el líquido cefalorraquídeo puede mostrar un aumento de proteínas y a veces algo de pleocitosis, aunque estos hallazgos no añaden nada al diagnóstico, por lo que sólo se los estudia ante la sospecha de otras enfermedades.

Únicamente en áreas endémicas se busca la presencia de anticuerpos para la enfermedad de Lyme.

Los estudios por imágenes en general aportan pocos datos. En la resonancia magnética los segmentos laberínticos e intracanaliculares del facial, y el ganglio geniculado pueden resaltar con el contraste, aunque esto no es específico y su sensibilidad es escasa; por lo que sólo se la reserva para casos de presentación atípicos. Típicamente el umbral auditivo no se ve afectado en la parálisis de Bell, sin embargo el reflejo estapedio puede estar reducido o ausente.

El electrodiagnóstico puede predecir los casos de mal pronóstico. De los pacientes que presentan dentro de las tres primeras semanas un $90 \%$ o más de degeneración fibrilar sólo el $50 \%$ alcanzan una buena recuperación funcional. Estos estudios no son de uso corriente en la práctica diaria, y se suelen utilizar sólo en protocolos de investigación.

\section{Diagnóstico diferencial}

Debe tenerse presente que existen otras causas de parálisis facial periférica de origen no "idiopático". Ellas son:

\section{1- Enfermedades Infecciosas}

a) Herpes zoster (Sme. de Ramsay Hunt): Alrededor del $27 \%$ de los pacientes con parálisis facial sin vesículas también tienen títulos elevados para herpes zoster por lo que se cree que el herpes zoster es la causa de casi un tercio de las parálisis anteriormente diagnosticadas como idiopáticas. El herpes zoster ha sido tradicionalmente asociado con el síndrome de Ramsay Hunt, presentando además de la disfunción del facial, disfunción cócleo-vestibular por afectación del VIII nervio, y aparición de vesículas cutáneas. El 75 al $100 \%$ de estos pacientes tienen títulos altos de anticuerpos anti herpes zoster virus. La incidencia del Sme. de Ramsay Hunt en pacientes con parálisis facial varía del 5 al $30 \%$. El paciente además puede presentar dolor y parestesias en el dermatoma afectado. Este dolor puede ser el único indicador clínico de que el causante del cuadro sea el herpes zoster y no el simple, dado que las vesículas pueden no necesariamente aparecer, o pueden hacerlo tardíamente en más de la mitad de los pacientes.

b) Otitis media: El 0,5 al 1\% de los casos de otitis media se complican con parálisis facial. Así mismo el $8 \%$ de las parálisis faciales se asocian con otitis medias. En estos casos la recuperación suele ser buena.

c) Otros gérmenes: lepra, sífilis, Enfermedad de Lyme (borreliosis).

2-Enfermedades granulomatosas

a) Sarcoidosis: en estos casos hasta el $33 \%$ puede ser bilateral.

\section{3-Traumatismos}

a) De cráneo: Luego de un traumatismo de cráneo con fractura de peñasco y hemorragia ótica.

b) Quirúrgico: Puede quedar como secuela de cirugías del oído, de neurinomas del acústico, de descompresión del ganglio de Gasser para neuralgia del trigémino, etc.

4-Parálisis facial bilateral Son alrededor del $1 \%$ de todos los casos. Se debe sospechar la presencia de otras patologías como sarcoidosis, linfomas, polirradículo-neuropatías agudas (Sme. de Guillain- Barre), etc.

La tabla 1 resume las causas y la incidencia de la parálisis facial aguda.

Tabla 1: causas e incidencia de parálisis facial aguda

\begin{tabular}{|cc|} 
Causas & Incidencia \\
- Parálisis de Bell & $72 \%$ \\
- Herpes simple tipo I & $84 \%$ \\
- Herpes zoster sin vesículas & $16 \%$ \\
- Síndrome de Ramsay Hunt & $7 \%$ \\
- Traumatismo & $4 \%$ \\
- Tumores & $4 \%$ \\
- Otitis media o colesteatoma & $3 \%$ \\
- Condiciones neonatales & $5 \%$ \\
- Otras causas inusuales & $4 \%$ \\
\hline
\end{tabular}

\section{Evolución}

En general la parálisis de Bell tiene un pronóstico aceptable. Todos los pacientes muestran algún grado de recuperación, aun sin tratamiento. Entre el 80 y el $90 \%$ de los pacientes se recuperan satisfactoriamente. Entre el 50 y el $70 \%$ de los pacientes logra una recuperación completa, y el $84 \%$ consigue una función casi normal. Por lo que algo más del $10 \%$ tiene una secuela menor. Un sexto de los pacientes puede quedar con debilidad moderada a severa, contracturas musculares, hemiespasmo facial o sincinesias. En las parálisis faciales causadas por herpes virus, zoster o simple, existe una significativa correlación entre el pico de severidad de la parálisis y la secuela. Los pacientes con debilidad parcial tienen un mejor pronóstico, con una recuperación total del $94 \%$. El pronóstico es peor en aquellos afectados por el virus de herpes zoster.

La mayoría de los pacientes comienza a mostrar alguna mejoría alrededor de los 10 días posteriores al inicio del cuadro y vuelven a la normalidad en 3 a 8 semanas. Si la recuperación no ocurre dentro de ese término, entonces es improbable que lo haga hasta 4 a 6 meses después, cuando el nervio vuelve a regenerarse. Para los 6 meses está claro quién tendrá secuelas moderadas a severas.

Al presente no existe ningún test confiable que pueda indicar quién logrará una recuperación completa.

La parálisis facial idiopática puede ser recurrente hasta en el 7\% de los casos.

La debilidad persistente es usualmente menos preocupante que los efectos de la regeneración aberrante.

Las anormalidades residuales, difícilmente perceptibles para el observador no entrenado, son

sincinecias (50\%) debilidad (25\%) contracturas $(10 \%)$ y lagrimeo anormal (6\%). La tabla 2 describe los indicadores de pobre pronóstico.

Tabla 2: indicadores de pobre pronóstico

1. Parálisis facial completa

2. Falta de recuperación en tres semanas

3. Edad superior a 60 años.

4. Dolor severo

5. Síndrome de Ramsay Hunt

6. Condiciones asociadas como hipertensión arterial, diabetes o embarazo.

7. Estudios electrofisiológicos con evidencia de una pérdida de más del $90 \%$ de las fibras. 


\section{Tratamiento}

En base a los mecanismos fisiopatológicos propuestos, se han utilizado diversas estrategias para tratar la parálisis facial idiopática, de esta forma los corticoides se han usado para reducir la inflamación; los antivirales para tratar la infección iniciadora del proceso y se ha intentado la cirugía para aliviar la compresión. Los principales objetivos del tratamiento en la fase aguda de la parálisis de Bell son lograr una rápida recuperación y prevenir complicaciones de la córnea. El tratamiento debe comenzar inmediatamente para inhibir la replicación viral y modificar el proceso fisiopatológico subsiguiente de afección del nervio facial.

\section{Cuidados oculares}

El cuidado ocular se focaliza en proteger la córnea de la sequedad y la abrasión debidas a la dificultad para la oclusión palpebral y al mecanismo tal vez deficiente en la producción de lágrimas. Se pueden aplicar gotas lubricantes en forma horaria durante el día y por la noche utilizar geles u óleos oftálmicos. También se ha implementado la oclusión ocular con parches u otros medios más económicos.

\section{Corticoesteroides}

Algunos estudios clínicos han sugerido que los corticoides usados en los primeros días de la parálisis mejorarían la evolución. Los beneficios serían modestos, aunque a costa de mínimos riesgos. Dos recientes revisiones sistemáticas concluyeron que la parálisis de Bell puede ser tratada en forma efectiva con corticoides en los primeros siete días, proveyendo un $17 \%$ extra de pacientes con buena evolución en adición al $80 \%$ que se recupera espontáneamente ${ }^{3,4,5}$. Dada la evidencia existente, se aconseja el uso de prednisona oral junto con aciclovir (dado que su adición parece incrementar el porcentaje de recuperación) en pacientes que se presentan con parálisis facial moderada a severa, preferentemente dentro de las 72 hs. La dosis óptima es desconocida. Si el paciente no presenta contraindicaciones precisas se indica $1 \mathrm{mg} / \mathrm{kg} / \mathrm{d}$ (máximo 80 $\mathrm{mg}$ ) durante una semana. No existe unanimidad en cuanto a la suspensión de la droga, hay quienes lo hacen en forma abrupta y quienes (la mayoría) proponen un descenso paulatino a lo largo de otra semana ${ }^{6,7}$

\section{Agentes antivirales}

El tratamiento con agentes antivirales resulta lógico de aplicar en la parálisis de Bell, debido a la fisiopatología planteada. El aciclovir, interfiere con la ADN polimerasa del virus del herpes e inhibe la replicación de su ADN. Un estudio prospectivo reciente demostró un beneficio significativo del aciclovir. Usando esta droga fue 1,22 veces más probable un resultado positivo, lo que implica un $18 \%$ adicional de beneficio sobre el $80 \%$ esperado para la evolución natural de la enfermedad ${ }^{8,9}$.

Debido a la relativamente pobre biodisponibilidad (del 15 a 30\%) se han estado probando nuevas drogas de este tipo, con mejores regímenes horarios de administración y con la esperanza de una mayor efectividad clínica. Se ha utilizado valciclovir (prodroga del aciclovir), el famciclovir (una prodroga del penciclovir), y la sorivudina.

En monoterapia, los esteroides han probado ser más efectivos que el aciclovir. Por lo que no se recomienda la utilización del aciclovir sin la asociación concomitante de esteroides, a menos que existiera una clara contraindicación para el uso de éstos.

\section{Terapia combinada}

Una revisión sistemática reciente encontró que los pacientes tratados con la combinación de aciclovir y prednisona tenían una mejor evolución que los tratados únicamente con prednisona. Esta diferencia fue determinante en particular en los pacientes en los cuales se inició el tratamiento dentro de los primeros tres días del inicio de la parálisis. Lo mismo aconteció con el uso de otro antiviral en un estudio prospectivo controlado por casos, donde se evidenció que los pacientes tratados con valaciclovir y prednisona tenían una mejor evolución que los pacientes tratados únicamente con prednisona.

En otro estudio se comparó el uso del aciclovir y de esteroides por vía oral y por vía endovenosa, no encontrándose diferencias significativas. Actualmente se recomienda la utilización por vía oral de aciclovir o valaciclovir asociado con prednisona en pacientes con parálisis faciales moderadas a severas que concurran a la consulta dentro de la primera semana de iniciado el cuadro, y preferentemente dentro de las primeras $72 \mathrm{hs}$.

\section{Tratamiento en niños}

Los niños con parálisis facial completa tienen peor pronóstico que los adultos. Sin embargo no existe evidencia que apoye el uso de corticoides o antivirales en chicos con parálisis de Bell.

\section{Herpes zoster sin vesículas}

Aunque $2.000 \mathrm{mg} / \mathrm{d}$ de aciclovir podrían no ser adecuados para tratar al síndrome de Ramsay Hunt con vesículas, parece ser ésta una dosis efectiva para pacientes con herpes zoster que se manifiesta sin vesículas. Basándose en la evidencia actual, en ausencia de significativo dolor o vesículas, esta dosis sería adecuada junto a los esteroides para tratar a la parálisis de Bell asociada al herpes zoster.

Cirugía

Los efectos de la descompresión quirúrgica del nervio facial aun no están claros y siguen siendo discutidos. El proceso acarrea no pocos riesgos, incluyendo convulsiones, pérdida auditiva, fístula de líquido cefalorraquídeo, y daño quirúrgico del facial. La complicación más común es la anacusia permanente unilateral. La evidencia no es convincente sobre la conveniencia de este tratamiento. Todos los estudios publicados, más de un centenar, son de clase IV. Sólo uno pareció demostrar una significativa asociación entre cirugía y mejoría. Por lo que actualmente no existe una recomendación basada en la evidencia para su utilización ${ }^{10}$.

\section{Terapia física}

Diversos tipos de terapias físicas, incluyendo masajes y ejercicios faciales, son recomendadas a estos pacientes, pero existen muy pocos estudios clínicos controlados que avalen su efectividad. Existen algunos reportes recientes de la eficacia del reentrenamiento facial (terapia mímica) con biofeedback.

\section{Otras recomendaciones}

En algunos casos más allá de las medidas generales del cuidado de la córnea y de las drogas por vía oral debe considerarse la posibilidad de ayuda psicológica de apoyo. Las secuelas a largo plazo pueden perderse si los pacientes no son seguidos al menos durante el plazo de un año. Si no hay evidencia de una recuperación completa se requiere el abordaje de un grupo terapéutico, que incluya al médico generalista, al oftalmólogo, al otorrinolaringólogo, a los psiquiatras, los fisioterapéutas, etc. Las sincinesias y los espasmos faciales son déficits comunes en las parálisis con recuperación parcial, y pueden ser exitosamente tratados con inyecciones locales de toxina botulínica.

La tabla 3 resume otros tratamientos emergentes para la parálisis facial periférica.

Tabla 3: Otros tratamientos emergentes

Con alguna evidencia de efectividad:
- Vitamina B 12.
- Oxígeno hiperbárico para pacientes que a pesar de haber recibido
el mejor tratamiento médico presentan mala evolución y gran
degeneración de las fibras nerviosas.
- Ejercicios faciales: Terapia mímica.
- Toxina botulínica para el hemiespasmo secuelar.
Con efecto incierto:
- Estimulación eléctrica transcutánea.
- Acupuntura.
En investigación actualmente:
- Nuevos antivirales: Famciclovir, sorivudina.
- Vacunación contra el virus de herpes zoster y herpes simple tipo
1 y 2 .
- Factores neurotróficos de crecimiento, agentes neuroprotectores.




\section{Conclusiones}

La parálisis de Bell es causada muy probablemente por el virus del herpes, mayormente del herpes simple tipo I y en algunos casos por el virus del herpes zoster.

La parálisis facial mejora luego del tratamiento oral combinado con prednisona y aciclovir.

El tratamiento de la parálisis parcial es controvertido ya que la tasa de recuperación espontánea es alta y sólo unos pocos pacientes no se recuperan si no son tratados.

El tratamiento es probablemente más efectivo si es comenzado dentro de las 72 del inicio del cuadro.

Un $20 \%$ de los casos de parálisis facial aguda tienen una causa diferente a la "idiopática", lo que debe llevar a una cuidadosa evaluación del paciente.

\section{Diego Bauso [ Médico Especialista en Neurología, Servicio de Neurología de Hospital Italiano de Buenos Aires. ]}

\section{Referencias}

1. Adour KK: Incidence and management of Bell's Palsy according to geographic distribution. En Fish U (Ed.): Facial Nerve Surgery. Proceedings of the 3rd International Symposium of Facial nerve Surgery. Birminhan, Al, Kugler Medical Publishers, 1977. Pp. 319-327.

2. Holland, N Julian; Weiner, Graeme M. Recent developments in Bell's Palsy. BMJ 2004;329:553-7.

3. Grogan P.M., Gronseth G.S. Practice parameter: Steroids, acyclovir, and surgery for Bell's Palsy (An evidence-based review). Report of the Quality Standards Subcommittee of the American Academy of Neurology. Neurology 2001;56:830-836.

4. Ramsey MJ, Der Simonian R, et al. Corticoesteroid treatment for idiopathic facial nerve paralysis: a metaanalysis. Laryngoscope 2000:110:335-41.

5. Austin JR, Peskin SP et al. Idipathic facial nerve parálisis: a randomized double blind controlled study of placebo versus prednisone. Laryngoscope 1993;103:1326-1333

6. Adour KK, Ruboyianes JM, et al. Bell's palsy treatment with acyclovir and prednisone compared with prednisone alone: a double blind, randomized, controlled trial. Ann Otol Rhinol Laryngol 1996;105:371-378.

7. Allen D, Dunn L. Aciclovir or valaciclovir for Bell's palsy (idiopathic facial paralysis). Cochrane Database Syst. Rev. 2004; (3):CD001869

8. Axelsson S, Lindberg S. Outcome of treatment with valacyclvir and prednisone in patients with Bell's Palsy. Ann Otol Rhinol Laryngol 2003 Mar;112(3): 197-201.

9. De diego JI, Prim MP, et al. Idipopathic facial parálisis: a randomized, prospective, and controlled study using signle-dose prednisone versus acyclovir trhee times daily. Laryngoscope 1998:108:573-575.

10. Gantz BJ, Rubinstein JT, et al. Surgical management of Bell's palsy. Laryngoscope 1999; 109:1177-1188.

Gilden D.H. Bell's Palsy. (Clinical Practice). N Engl J Med 2004;351:1323-31.

Viñetas clínicas coleccionables

\section{PITIRIASIS VERSICOLOR}

Tomás Owens (h). Chairman, Department of Family Medicine INTEGRIS Baptist Medical Center. Associate Director-Great Plains Family Medicine Residency Program. Associate Professor Department of Internal Medicine, Department of Geriatric Medicine. Department of Family and Preventive Medicine. University of Oklahoma Health Sciences Center.
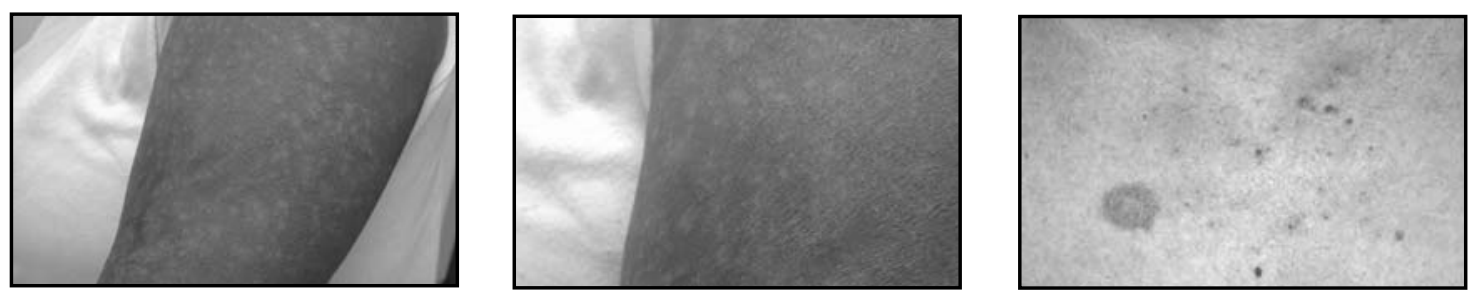

- "Estas fotos pueden verse en colores en www.evidencia.org".

\section{Presentación clínica}

Conocida anteriormente como tiña versicolor, se trata de una erupción macular con márgenes irregulares y confluentes. Puede ser blanquecina o más oscura que la piel circundante y aparece primordialmente sobre el cuello (respetando la cara ) hombros, brazo y abdomen. Tras rozarla vigorosamente o incluso de forma espontánea, si se la observa detalladamente, puede evidenciarse una descamación furfurácea ligera. El paciente refiere exacerbación de las lesiones con sudor y calor.

La apariencia puede ser contraria en las personas de diferente color de la piel (p.ej. tez blanca vs. oscura) de allí el prefijo "versi". Con la luz de Wood la erupción luce verde fosforescente.

\section{Epidemiología}

Casi $50 \%$ de los adolescentes de los climas tropicales sufre pitiriasis versicolor. Rara vez aparece antes de los 15 años de edad.

\section{Fisiopatogenia}

El agente etiológico es Pityrosporum orbiculare, antes conocido como Malassezia furfur. Es un organismo oportunista que vive normalmente en la piel y crece desproporcionadamente en presencia de humedad y calor.

\section{Tratamiento}

Se trata con la aplicación de champú de sulfuro de selenio al 2,5\% o ketoconazol en forma diaria durante 15 a 45 minutos, seguido por un baño, durante siente días. Otra alternativa es el ketoconazol a una dosis de $400 \mathrm{mg}$ en una dosis única por vía oral, repitiéndola a la semana. Luego de finalizar el tratamiento, la repigmentación puede tomar más de 60 días. 